\title{
Türk Mitolojisinde Trickster Karı (Azerbaycan Folklor Örnekleri Esasinda)
}

\author{
Şebnem ESEDOVA ${ }^{1}$
}

Öz

Trickster imgeler uzun yıllardır folklor araştırmacılarının araştırma hedefidir. Dünya folklorunda trickster imgeler üzerine çalışmalar yaygınlaşmıştır. Tilki, tavşan, maymun, şaman, bilge adam, büyücü ve diğer imgeler analitik psikolojide ve halk bilimi çalışmalarının içinde bir hileci- trickster olarak yer alıyor. Makalemizde şimdiye kadar ele alınmamış yaşlı kadın imgesinin trickster özeliklerinden bahsedilmektedir. Belirtelim ki, mitlerden başlayarak, genellikle efsane ve destanlarda, masallarda ortaya çıkan karı imgesi bazı özelliklerine göre bir hileci olarak düşünülebilir. Halk edebiyatında karı imgesi mitolojik ve demonoloji imgedir. Aynı zamanda folklor metinlerinde karı mizah yaratan karakterdir. Bu mizah karının mitolojik karakter Trickster'le yakınlığına dayanıyor. Karının da trickster olduğunu düşünmek için birçok sebep bulunmaktadır. Öncelikli olarak bu sebepler açıklanmaktadır. Bu nedenle makalenin ilk bölümünde, karı imgesini trickster eden özellikleri irdelenmektedir. Karı karakteri kimi zaman iyi, kimi zaman kötü, bazen komik, bazense dramatik durumda, kâh bilge, kâh sinsi, k1lık değiştiren karakter olarak ortaya çımaktadır. İkinci bölümde ise, trickster karıdan trickster keçelin ninesi, annesi gibi bahsedilmektedir. Amaç karı karakterinin diğer trickster karakterler sırasında yerini tanımlamaktır.

Anahtar Kelimeler: Trickster, Yaşlı kadın, Düzenbaz, Keçel, Mizah

\section{Trikster Old Woman in Turkish Mythology (Based on Azerbaijani Folklore Samples)}

\section{Abstract}

Trickster images have been the research target of folklore researchers for many years. Studies on trickster images have become widespread in world folklore. Foxes, rabbits, shamans, wise men, magicians and other images are included in analytical psychology and folklore as a trickster. In our article we will talk about the trickster features of the old wife image. Starting with myths, usually in myths and epics, the image of the old woman emerging in tales can be considered as a trick according to some features. The image of old woman in folk literature is mythological and demonological. At the same time, old woman is the character that creates humor in the folklore. This humor is based on the proximity of the mythological character trickster with the character of a woman. There are many reasons to think old woman is a trickster. We need to explain these reasons first. So, in the first part of the article had been talked about the features that made old woman a trickster. Sometimes the old woman is good, sometimes bad, sometimes funny, sometimes dramatic situations, sometimes wise, sometimes sly. In the second part, it has been talked about the relationship between trickster bald and the trickster old woman. The aim is to define the place of the old woman among the other trickster characters.

Key Words: Trickster, Old woman, Artful, Bald, Humor

\section{Atıf İçin / Please Cite As:}

Esedova, Ş. (2020). Türk mitolojisinde Trickster Karı (Azerbaycan folklor örnekleri esasında). Manas Sosyal Arastirmalar Dergisi, 9(3), 1934-1941.

Geliş Tarihi / Received Date: 08.11.2018

Kabul Tarihi / Accepted Date: 22.04.2020

\footnotetext{
${ }^{1}$ Doktora öğrencisi, Azerbaycan Milli Bilimler Akademisi Folklor Enstitüsü, shebnem.vagif@mail.ru ORCID: 0000-0002-2672-9583
} 


\section{Giriş}

Mitlerden bașlayarak, efsanelerde, destan ve masallarda, atasözü ve deyimlerde sıkça rastlanan karı karakteri bazı özellikleri nedeniyle bir hileci, trickster olarak düşünülebilir. Trickster nedir? Araştırmacılar bu soruyu farklı șekillerde yanıtlamıșlardır. Trickster'in karakterinde, iyi ve kötü hakkında ilkel senkretizm anlayışııı yansıtan zıt başlangıçlar birleşir (Кинжалов, 2008, s. 423). Araştırmacılara göre, hileci - Trickster aşağıda sıralanan özelliklere sahiptir; 1 . Zıt ve sınır 2. Sahtekârlık ve yalan söyleme 3. Dönüşme yeteneği ve kilık değişme 4. Durumu değiştirme (Hynes ve Doty, 1993, s. 33-45).

Trickster geleneği yok etmek, dünyanın düzenini bozmak ve kaosa neden olmak için ortaya çıkmıştır. Aslında düzensizlik hayatın bir parçası, Trickster da bu düzensizliğin canlı ruhudur (Керенъи, 1999, s. 257). Trickster'in bir diğer özelliği, bir kadın kıllı̆̆ına girmesi ya da cinsiyet değiştirme eğiliminde olmasıdır. Trickster üzerine yaptığı son çalışmalarından birinde Ana Stefanova, tricksterin, her tür kutsal ve tartışmalı özelliği, gülünç, şakacı, kötü ve düzenbaz gibi çelişkileri, tek bir bütün halinde birleștiren bir kahraman olarak dünyadaki tüm kültürlerin bir parçası olduğu sonucuna varmaktadır. Trickster özellikle erkek ya da kadın değildir, evrensel tahtel şuurla dış görünümü kendinde birleştiren interface'dir, mizah kahramanıdır (Stefanova, 77).

Zaman-zaman Trickster karakteri ilahlaşmıştır. Ancak Trickster'i sadece doğasına göre ilah sayma daha doğru olacaktır. C. G. Jung'a göre Trikster- hileci, insanüstü niteliklerine göre insandan da üstün olan, ama aptal ve bilinçsiz olması nedeniyle ondan aşağıda yer alan ilahi-hayvan doğasına sahip ilkel bir kozmik yaratıktır (Юнг, 1999, s. 276). Trickster isimli kitabın yazarı Paul Radin Trickster'in doğasındakı ilahı şöyle anlatmaktadır;tricksterya ilahi güçe eşit tutulmuşyada ilah olsa da sonradan bu tür doğadan uzaklaşmıştır (РаАин, 1999, s. 234). Trickster kargadan bahseden E. Meletinski'nin kavramina göre trickster "yukar1aşağı", "kış-yaz", "erkek-kadın" ve diğer çelişkilerde "mediator" rolünü (herhangi bir anlaşmazlık halinde, tarafların ortak bir noktada buluşmalarını sağlayan) üstlenmektedir (Мелетинский, 2000, s. 187). Aslına bakılırsa, trickster yalanc1, kurnaz, komik, kılık değiştiren, mevcut olduğu yerde kaosa sebep olan, demonizm özelliklerine sahip bir karakterdir. İnsan da, hayvan da trickster olabilir. Mitolojik metinlerden folklor metinlerine dönüşüm yapan karı karakteri trickster sayılabilir. Mitolojik metinlerinde karı karakteri Al karıs1, Albastı, Su ninesi, Umay ise, folklor metinlerinde kar1, Al karısi'nın, Albastı'nın, Su ninesi'nin, Umay'ın özelliklerini taşıyan ocak hamisi, dadı, rüya tabircisi, küp karısı, büyücü, tabip, hatta dev karısıdır. Kar1 canlılar ve ölüler, insanlar ve tanrılar arasında bağlantı kuran tricksterdir. Karının mitolojik kökeninden kaynaklanan hileci çizgileri fazladır. Tanrı arkaik olduğu kadar fazla tricksterdir (Гаврилов, 2006, s. 360). Hilecinin tüm hareketleri üst yapıda komik, alt yapıda ise ciddi anlam taşımaktadır (Quliyev, 2016, s. 141). Hileci karı komik anlamda bazen bilgeliğin, bazen aptallığın bazense düzenbazlığın parodisini göstermektedir. Ciddi anlamdaysa karı karakteri Ulu Ana'dan dönüşüm yapmış, toplumda söz hakkına sahib yaşlı kadındır. Karı aynı zamanda şamandır. K. G. Jung'a göre trickster özellikleri şaman karakterinde de bulunmaktadır. Çünkü şamanlar da zarar verdikleri kimsenin kurbanı olmayı sevmektedirler. K. G. Jung şamanın uykuda iken kurtarıcıya dönüşmeyi, aynı zamanda insanlaşmasını da onun trickster'e ait özelliklerinden olduğunu ifade etmektedir (Юнг, 1999: 266). Örneğin, Ain Şain Şikşirge Altay destani'nda Emegen karı'da hilecinin birkaç özelliği görülmektedir. Olökşi'nin üçüncü çocuğunun kız veya erkek olması sırrını öğrenmek için Emegen karıyı davet etmektedirler. Destan boyunca Emegen karı'nın kilık değiştirdiği bilinmektedir (Türk xalqları folkloru, 2016, s. 55). Veyahut Begen Sagaan Toolay Altay masalında trickster karı Celbegedir. Celbege yeraltı dünyasında yaşamaktadır. Onun hiçbir zaman sönmeyen ateşi bulunmaktadır. Ateş koruyucusu Celbege karı hilecidir. Yanına ateş için gelmiş prensesi hile ve yalanla aldatmaktadır. Celbege, yere yattı̆̆ı zaman kalkamadığını, ayakta olduğu zaman ise yatamadığını söylemektedir. Prenses ateş alıp gittikten sonra hileci Celbege karı her gece kalkıp ateşin izini takip ederek prensesin kanını içerek geri dönmektedir (Сказки и предания а^тайских тувинцев, 1994: 85). Trickster aynı zamanda kurucu-yaradan, yok eden-dağıtan hem alan, hem veren, diğerlerine tuzak kuran, kendi kazdığı kuyuya kendisi düşen bir imgedir (Радин, 1999, s. 235). Sözü edilen Emegen karı ise, Celbege karı gibi trickster özellikleri taşıyan karakterlerden daha fazla özellikleri barındırmaktadır. Azerbaycan folklor örneklerinde de bu tür karakterlere fazla rastlanılmaktadır.

\section{Karı Karakterini Trickster Olarak Belirleyen Özellikler}

Folklor kahramanı olan karı komik figür olarak ilgi çekmektedir. Metinler incelendiğinde karı imgesinin ciddi olduğu zaman bile mizah yarattı̆̆ görülmektedir. Peki, karakteri komik yapan hangi özellikleridir? 
Muhtar Kazımoğlu'nun Gülïs̆̈̈n Arxaik Köklłri (Kazımoğlu, 2005), Xalq Gülïş̈̈nün Poetikası (Kazımoğlu, 2006) eserlerinde karakteri komik yapan belirtiler incelenmiştir. Bu belirtilere düzenbazlik, kurnazlık, açgözlülük, kılık değişme gibiözellikler örnek verilebilir. Şimdiye kadarki araştırmalara göre bu belirtiler trikster'e aittir. Kurnaz, hileci ve yalancı sıfatlan folklor metinlerinde ortaya çıkan yaşlı kadın imgesinde de bulunmaktadır. Yaşlı kadın amacına ulaşmak için bu özellikleri kullanmaktadır. Kahramanın hedefine ulaşmak için bir hileci olduğunu ileri süren Fidan Qasımova, zamanla, kültürel kahramandan ilkel hileci karakterin ayrıldığını ifade etmektedir. Hileci ya kültürel kahramanın kardeşi gibi ya da ikinci şabsiyet gibi anlatılmaktadır. Bilimde trickster ismi verilen bu imge kendinde iblis ve mizah özellikleri taşımaktadır (Qasımova, 2012, s. 145). Demonik özellikler karı karakterinin mitolojik kökeninden kaynaklanmaktadır. Mitolojik özelliklere sahip karı karakterini iki aşamada görmek mümkündür. Birinci aşamada karı yaratıcı kadın ve başlangıç, Ulu Anadır. İkinci aşamada ise mitolojik karı herkes için tehlikeli özellikler kazanmış, demona çevrilmiştir. Yani karı imgesi karı olana kadar yaratıcı başlangıç olmuş, sonra iye olmuş, daha sonra olumsuz taraflara sahip tabiatüstü varlığa dönüşmüş, Al karısı olmuş, daha sonra şaman olarak halk edebiyatında yerini tutmuş, en sonunda olumlu ve olumsuz yönlere sahip karı nineye dönüşmüştür (Hüseynova, 2018). Ve karı ninede artık komik özellikler oluşmuştur. Yani karının demonizmine komik belirtiler de eklenmiştir.

Trickster karı karakterini araştırmak için karakterin komik yanlarını ortaya çıkarmak gerekmektedir. Karıyıtrickster'e dönüştüren önemli özelliklerinden biri hileci veyahut düzenbaz olmasıdır. Kurnazlık ve aptallık, olumlu ve olumsuzu, iyi ve kötüyü kendinde birleştirmektedir (Kazımoğlu, 2005, s. 37). Karının hem olumlu hem de olumsuz yanı bulunmaktadır.

\section{Düzenbazlık}

Gerek olumsuz gerekse de olumlu karı imgesinde düzenbazlık karakteristik bir özelliktir. Bu özelliği ile karı iyi ya da kötü işler yapar, insanları esaret altında tutar, onları kendine inandırır, kahramanı diğer dünyaya gönderir yahut doğrudan kahramana yardımcı olur. Tacir Qəmər (Tüccar Kamer) masalındaki karı düzenbazlıkla tüccar Kurbanı, tüccar Kamerin evine getirir. Karının kurduğu hileler tüccar Kurbanın kötü emellerini hayata geçirmeye yardımcı olur. Karı ustaya içeriden açılıp, içeriden kapatılan ve dört tarafindan da bakmak için göz yerleri bulunan bir sandık yaptırmaktadır. Burada karının sinsiliği, yalancılığı ortaya çıkmaktadır. O, elinde bir asa, bir siyah tespih kendini hacı gibi kaleme vermekle Tüccar Kamer'in karısını aldatmaktadır (AFK-2., 2007, s. 189). Halk edebiyatı örneklerinde kahramanın düşmanlarına her zaman düzenbaz karılar yardım etmektedir.

\section{Dönergelik}

Düzenbazlı̆ı̆n bir belirtisi dönergelike ve yahut kellk değģştirmedir. Kendini saklayıp başka bir forma girmenin arkaik anlamı kahramanın değişerek diğer dünya sakinlerinin görünümüne uygun bir görünüm alması inancı ile ilgilidir (Kazımoğlu, 2005, s. 159). Folklor metinlerinde karı kılık değiştiren bir karakterdir. Tacir Qamər masalında karının zevvar - hacı sûretine bürünmesi kılık değiştirmedir. Burada karının elbise değişmesi sıradan gelebilir. Aslında tüccarın eşini inandırmak için karının bu yöntemi kullanması gerekmektedir. Çünkü karı kendi elbisesiyle gelseydi onun toplumdaki düzenbaz olarak bilinmesi sebebiyle tüccarın eşikarıya inanmazdı. Ancak, hacı elbisesi giyinmesinden sonra karı Müslüman görünümü alarak etrafindakiler için daha fazla inandırıcı hale gelmiştir.

Azerbaycan halk masallarında karının kılık değiştirmesine ait yeterli örnekler bulunmaktadır. Örneğin,

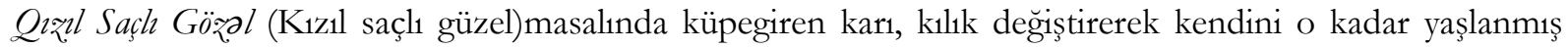
olarak göstermiştir ki, kimse onun gerçek kimliğini anlamamıştır (AFK- 2., 2007, s. 115). Köynək (Gömlek) masalında melek, geyik donuna girmiş karı olarak görülmektedir. Ilan Oğlan (Yılan oğlan) masalında ise (AFK- 1., 294) karı, karatufan,sis, kara bulut şeklini almıştır.

Kılık değiştirmek, mitolojik imgenin fonksiyonunu gerçekleştirmesi için önemli araçtır. Yani

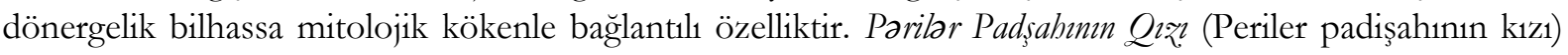
(AFK1., 2006, s. 167) masalında köpek karı bulunmaktadır. Nitekim ayinler sırasında güçlü şamanlar kurt, kartal gibi hayvanların biçimine girerken, zayıf şamanlar köpek şekline girmekte ve köpek genellikle yeraltı dünyasına inerken kullanılmaktaydı... Köpek, Budizm'de tenasüh inancına göre günahkâr insanların üçüncü kez doğduklarında büründükleri hayvan sûretlerinden biri olarak kabul görmektedir (Çoruhlu, 2002, s. 154). Sihirli masalların kahramanları hem hayvan hem de insandırlar. Bu kahramanlar insanlar alemine ait olup hayvan içgüdüsünü değil de, insanın hayvan içgüdüsünü yansıtmaktadır (Франц, 2004: 26). Simamın Nağ̊l masalında karı çeşitli sıfatlara bürünmektedir (AFK-1., 2006, s. 203). Siman erkek çocuklarını çalan 
hırsızı bulmak için diğer dünyaya gitmektedir. Onun ıssız yerde rastladığı karı, geyik, horoz, fare sûretini almaktadır (AFK-1., 2006, s. 218).

Kılık değiştirmenin örneği Dede Korkut destanında Kısırca Yenge ve Boğazca Fatma imgelerinde de görülmektedir. Onlar düzenbazlıkla Banı Çiçek'e yardım etmektedirler. Düzenbazlık, destanlarda mizaha zemin oluşturan temel motiflerden biridir. Bu motifin kahramanlık destanlarında daha zengin ifadeleri bulunmaktadır (Kazımoğlu, 2006, s. 170). Banı Çiçek'in kaftanını giyen karılar Banı Çiçek gibi düğüne katılmaktadırlar. Kısırca Yenge ve Boğazca Fatma'nın sembollerinden biri bu kaftandır. Kaftanın belirleme, sözleşme sembolü olduğunu söyleyen Kamran Aliyev kaftanın aynı zamanda tanınma sembolü olduğu fikri üzerinde durmaktadır (Oliyev, 2011, s. 89). Yani düğündekiler Banı Çiçek'i bu kaftanla tanyyorlar, kaftanın içerisinde Banı Çiçek'in olduğunu sanıyorlar. Özge örtüsüne bürünüp kendi görkemini gizleyen folklor kahramanı, o dünyaya ait varlıklardan korunduğu gibi, bu dünyadaki düşmanlarından da korunabilmektedir (Kazımoğlu, 2006, s. 212), Kısırca Yenge ile Boğazca Fatma Banı Çiçek donuna/formuna girmekle onu yabanc1 insanlardan, etrafindakilerden koruyorlar. Fakat komik duruma düştüklerinden Kısırca Yenge'nin ve Boğazca Fatma'nın düzenbazlığı yarıda kalıyor. Ama yine de Kısırca Yenge ve Boğazca Fatma destanın genelinde düzenbazdırlar ve sonuna kadar sebep oldukları mizah onları düzeltmek içindir. Başkasıyla ilişki kurmaya aldırış etmeden otomatik biçimde kendi yolunda giden kişi gülünç bir konumdadır. Gülme onun bu dalgınlığını sslah etmek, onu rüyasından uyandırmak için vardır. (Bergson, 2014, s. 88). Mizah karakteri olan karı gerçekten hikâyenin genelinde düzenbaz olarak kalmaktadır. Bergson'un kahkaha hakkındaki fikirleri bir araya toplandığında böyle bir sonuca varıla bilmektedir, karakteri komik yapan hareketlerindeki "katıllıtır" ve Bergsona göre başkalarının kusuru o zaman komik kabul edilebilir ki, bu kusur ahlak dıșı değil, toplum dıșı olur (Bergson, 2014, s. 90). Feinberg ise Miz̧ahın Sırr eserinde Plato, Plutarch gibi önemli kişilerin araştırmalarına dayanarak, mizahta her zaman birinin cehaleti, gururu ve ikiyüzlülügü eleştirinin hedefi yapıldığını, buradaki amacın birilerinin fiziksel veya ahlaki kusurunu düzeltmek olduğunu ifade etmektedir (Feinberg, 2004, s. 107). Feinberg ise mizahta toplumsal kusuru değil, kişisel kusuru esas saymaktadır. Aslında bireyin kusurunu mizahla düzeltmeye çalışılmasıtoplum için örnek olmaktadır.

\section{Aptallik}

Tricksterin tipik özelliklerinden biri aptallıktır. Kerenyi'ye göre aptallıkla kurnazlık her zaman birbiriyle ilişkilidir ve bunun en iyi örneği mitolojidir. Mitolojide kurnazlık daha temeldir ve aptallık ikinci plandadır, yani kurnazlık sonradan aptallı̆̆a dönüşür (Кереньи, 1999, s. 251). Dəlisov Arvad (Çılgın karı) masalında bu açık bir şekilde görülmektedir. Nehirden altın dolusu küp bulan karı eşi Ramaz̧an geldiğinde altmı harcanz deyince tüm altını Ramazan adlı kızılcık satıcısına vermektedir (AFK-7., 2008, s. 323-327). Burada aptalliktan doğan komedi görülmektedir (Kazımoğlu, 2006, s. 142). Allah Ruそusu (Allah'ın rizkı) masalında ise karı ile oğlunun aptallığı onları mal-mülk sahibi yapmaktadır. Ormandan küp bulan karı onu eve getirmek için oğluna çok yalvarır. Ama oğlu ræækı veren Allab eve de getirecek demektedir. Altından haberi olan komşu onlara sahip çıkmak istemektedir. Ancak küpün üzerinde kıvrllıp yatan yılan yüzünden komşu altınlara sahip olamamaktadır. Kötü niyetli komşu yılan dolu küpü evin bacasından boşaltmakta ve o sırada yılanlar altına dönüşmektedir (İsmayılov, 1993, s. 318). Masalda aptallık akıllı olmanın parodisidir. Proppa göre, parodi o zaman komikliğe dönüşmektedir. O, parodi olunanın içsel zayıflığını ortaya koymaktadır (Propp, 36). Buradada karı ile oğlunun aptallığı abartılarak onların kusuru gösterilmektedir. Bu yüzden de karı ile oğlu mizahın hedefidirler.

\section{Açgözlülük}

Karı imgesine has diğer bir özellik açgözlülüktür. Masal ve destanlarda iyiniyetli karılar bile açgözlü

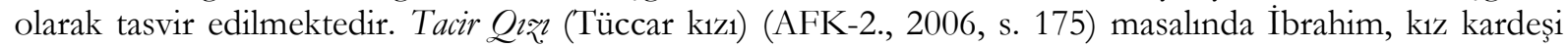
yalnız kalmasın diye onunla birlikte kalmak için karı bularak eve getirmektedir. İman sahibi olan bu karı altın için her şeyinden vazgeçmektedir (AFK-2., 2006, s. 182). Ve yahut, Cinlar Padşabınn Qıそ? (Cinler padişahının kızı) masalında açgözlü karı padişahın oğluna nasihat vermek için para istemektedir (AFK-2., 2006, s. 40). Diğer Azerbaycan masalı Torç Oğhinda açgözlü karıların hazin sonundan bahsedilmektedir. Diğer dünyaya giden kahraman iki kapı arasında oturmuş bir karıya rastlamaktadır. Bu karının önünde kan ve arpa ekmeği bulunmaktadır. $\mathrm{O}$ arpa ekmeğini kana bandırıp yemektedir. Karının söylediklerinden anlaşılmaktadır ki, bir zamanlar açgözlü, kötü niyetli olduğu için tanrı onu böyle cezalandırmıştır (AFK-1., 2006, s. 94). Yukarıda bahsedilen Celbege karı da açgözlüdür. Celbege karşısına çıkan her bir şeyi 
yemektedir. Yalnız olumsuz karılar trickster özelliklerine sahip değildirler. Öyle ki, kahramanın yardımcısı olan karllar da trickster olabilirler.

\section{Trickster Karının Trickster Oğlu-Keçel}

Karı imgesinden bahs edildiğinde keģel (kel) karakterinin de üzerinde durmak gerekir. Çünkü keçel imgesi folklor metinlerinde genellikle karıların oğlu, torunu olmaktadır. Karı gibi keçel imgesinin de mitoloji kökeni demonik varlıklardır. Keçel karakterinin bulunduğu metinlerde mutlaka karı karakterine de rastlanılmaktadır. Azerbaycan folklorunda keçelin başka demonik varlıklarla ilişkisini yansıtan öyküler esasen, düzenbazlık motifi üzerinedir (Kazımoğlu, 2006, s. 80). Kar1-keçel motifli masallarda genellikle aktif taraf keçel olmaktadır. Karının aptallı̆̆ı ile keçelin hileciliği masallarda,kurguyu ilgi çekici hale getiren bir motif olarak sunulmaktadır. Masallardaki Trickster, yani hileci imgelerin de hırsızlık, komiklik, kurnazlık ve benzeri özellikler taşıdığını ifade eden Fidan Qasımova, bir masalda sinsi olarak hareket eden imge, diğerinde saflık veya aptal özelliklerine sahip ola bildiğini belirtmektedir. Bazı masallarda bunlardan birinin aldatıc1 olduğunda diğerinin aldanan olarak görüldüğünü de ifade etmektedir (Qasımova, 2012, s. 135). Bu fikir kar1 karakteri için de geçerlidir. "Fərasətli Keçəl" (Ferasetli kel)(AFK-3., 2006, s. 154) masalında olduğu gibi. Burada keçelin karı ninesi aptaldır. Onun bu hali keçelin hayatını tehlikeye sokmaktadır. Tabii ki, keçelin bundan haberi olana kadar. Öyle ki, açgözlü karı aptal karı’yı kandırmakla keçelin hükümdardan çaldığı devenin yerini öğrenir. Fakat keçel karıdan hızlı hareket edip hile ile onu cehenneme gönderir (AFK-3., 2006, s. 157). Farasatli Kę̧al masalında karının torunu k1lık değiştirmektedir. Kız, doktor kilığında olan keçel sonunda gerçekten hükümdarın veziri olmaktadır. Bu iki hileciden biri düzenbazlık yapmasaydı o zaman mitolojik kökten uzak düşmüş olurlardı. Çünkü Trickster bu dünya ile öbür dünya arasında köprüdür. Keçel hükümdara, vezire veya diğer dünyada karşılaştığı demonik varlıklara özel fiziksel güç göstermekle galip gelmiyor, aksine o, hile yaparak, yalan söyleyip, düzenbazlık edip zafer kazanıyor. Veyahut Keçal Mahammad (AFK-9., 2008, s. 271) masalında keçel Fatı karının torunu gibi takdim edilmektedir. Keçel Muhammed'in ninesi Fatı karı da kurnazdır. Fatı karı torununun bütün işlerinden önceden haberdardır. Ancak masalda Keçel Muhammed'e yardım eden diğer karıdır. Bu karının yardımı ile Keçel Muhammed padişahın ona verdiyi görevlerle baş etmektedir. Keçel karakterinde de karıda olduğu gibi aptallık özelliği bulunmaktadır. Fakat keçel karakteri sonradan bilge sıfatı almakta, karı ninesinden farklı olarak ağırbaşlı haraket etmektedir. Sihirli masal kahramanları ironik olsalar bile sonradan ciddi davranmak onlara özgü belirtidir (Đsgər, 2017, s. 48).

Folklor metinlerinde kar1-keçel her zaman nine-torun statüsünde olmuyorlar. Nine-torun olmadıkları zaman masallarda karı-keçel çatışması meydana çıkıyor. Komik folklor metinlerinde çatışma keskin farkı olan olumlu ve olumsuz taraflar arasında değil de kesinlikle orta pozisyonda dayanan taraflar arasında gerçekleşiyor (Kazımoğlu, 2006, s. 239). Örneğin, Kę̧al (Keçel) (AFK-9., 2008, s. 316) masalında mağarada yaşayan cadı karı keçeli pişirb yedi ejderha oğluna vermek istiyor. Burada Keçel'e düzenbazlı̆̆ı kurnazlı̆̆1 yardım etmiyor. Ona fiziksel güç gerekiyor. Demonik varlıklar olan yedi kardeş ejderha ile savaşmak için Keçel bu gücü kazanıyor. $O$, ormanda bir çeşmeden akan suda yıkanıyor ve o zaman kafasında saçlar çıkıyor. Tüy, tükenmez gücün simgesidir. Masalda tüysüzlük zayıflığın, tüylülük ise bahadırlığın işareti olarak kendini göstermektedir (Kazımoğlu, 2006, s. 72). Belirtilmesinde fayda var, tıpkı karı gibi hileci de her zaman oyundan galip ayrılmıor. Karı-keçel karşılaşmasında hileci karı hileci keçelin hilesine kurban gidiyor. Cehennemlik olan karı diğer dünyada kalmalı, keçel ise kızılsaçlı kahramana dönüştükten sonra kendi dünyasına geri dönmelidir. Karı karakteri diğer dünyayı sembolize ediyorsa, keçel kızılsaçlı kahraman gibi olağanüstü özelliği ile diğer dünyaya bağ1 olan ve kendi gücünü aynı sihirli alemden alan bir kahramandır (Kazımoğlu, 2006, s. 81). Türk mitolojisinde kar1 ile keçelin bir bütünden kopmas1 doğrulanmıştır. Bu imgeler Ulu Ana bütününden kopanlardır.

\section{Sonuç}

Sonuç olarak, halk edebiyatında yardımcı karakter olan karı aynı zamanda trickster imgesinin özelliğine de sahiptir. Çünkü trickstere ait özellikler karı karakterinde de hâkimdir. Örneğin, karı da düzenbazlıkla insanları etkiler, onları kendine inandırır, kahramanı dönüşü olmayan yöne yönlendirir, ya da doğrudan kahramana yardımcı olur.

Ayrıca, düzenbaz karı hedefine ulaşmak için kılık değiştiren karıdır. Onun k1lığa girebilme, kılık değiştirebilme özelliği mitolojik kökeninden kaynaklanmaktadır.

Karı aynı zamanda açgözlüdür. Bazen onun hileci olmasına açgözlü olma özelliği neden olmaktadır. Karının aptallık özelliği de bulunmaktadır. Çoğu zaman aptallığı karının yardımcısıdır. Örneğin, bazı 
masallarda karı kendini aptal göstermekle insanların gazabından koruyor. Çünkü insanlar aptal karını hiç bir zaman ciddiye almıyorlar. Bu durumdan faydalanan yaşlı kadın kendi planlarını uyguluyor. Anlaşıldı̆̆ı gibi karıda da tricksterin yukarıda sıraladığımız özellikleri bulunmaktadır.

Ayrıca belirtilmelidir ki, trickster karı trickster keçel ile yan-yana dururken daha komiktir. Kar1-keçel konulu metinlerde çoğu zaman akrabadırlar. Yani karı bazen keçelin ninesi, bazen annesidir. Çoğu zaman karı keçele, keçel de karı ninesine yardımcı olmaktadır. Karının aptallığı ile keçelin kurnazlığı masallarda paralellik oluşturmaktadır. Akraba (anne-oğul, nine-torun) statüsünde olmadıkları zaman, keçel ile karı arasında çatışma hâkimdir. Çatışmada çoğunlukla aktif taraf keçeldir. Karı-keçel motifli masallarda keçelin düzenbazlığı, karınınsa aptallığı fazladır. Genellikle, tüm bu özellikler karı karakterini komik yapmaktadır. En ciddi durumda bile karı mizah yaratmaktadır. Komik yöndeki karıda bilgeliğin, aptallığın ve düzenbazlığın parodisi bulunmaktadır.

Genel olarak folklorda sıkça rastlanılan karı imgesinin önemli özelliği, trickstere yakınlığ 1 ile yani onunla neredeyse aynı görevi üstlenmesinden kaynaklandığı söylenebilir. Folklorun destan, masal, fikra, atasözü, deyimlerde, inançlardave diğer türlerinde trickster karı imgesi önemli karakter olarak görülmektedir. Araştırmadan da anlaşılacağı gibi, dünya ve eski Türk mitolojisinden dönüşüm yapan karının trickster özelliklerine Azerbaycan folklor örneklerinde de rastlanmaktadır.

\section{Etik Beyan}

"Türk Mitolojisinde Trickster Karn (Ažerbaycan Folklor Örnekleri Esasında)" başlıklı çalısmanın yazım sürecinde bilimsel, etik ve alıntı kurallarına uyulmuş; toplanan veriler üzerinde herhangi bir tahrifat yapılmamış ve bu çalışma herhangi başka bir akademik yayın ortamına değerlendirme için gönderilmemiştir.

\section{Kaynakça}

Az̧rbaycan Folkloru Külliyatı. (2006). 1-ci cild. Hazırlayan İsmayılov H., Oliyev O., Bak1. Az̧rbaycan Folkloru Külliyatı. (2006). 2-ci cild. Hazırlayan İsmayılov H., Oliyev O., Bakı. Az̧rbaycan Folkloru Külliyatı. (2006). 3-cü cild. Hazırlayan İsmay1lov H., Oliyev O., Bakı. Az̧rbaycan Folkloru Külliyatı. (2008). 7-cicild.Bak1.Hazırlayanİsmay1lov H., Oliyev O., Bak1. Az̧rbaycan Folkloru Külliyatı. (2008). 9-cu cild.Bakı.Hazırlayanİsmayılov H., Oliyev O., Bak1. Bergson H.(2014). Gülme. Gülüncünanlamı üzerine deneme. Çeviren: Devrim Çetinkasap. Bəydili C.(2007). Türk mifoloji obrąlar sistemi: strukturvafunksiya (monoqrafiya). Bak1. Çoruhlu Y. (2002). Türk mitolojisinin ana hatlar, Kabalcıyayınevi. İstanbul.

Ofzələddin Ә. (2017). Az̧rbaycan sehrli nağıllarnnda qahraman, Bak1, Elm və təhsil.

Oliyev K. (2011). Eposun poetikası: "DadaQorqud” va "Koroğlu”. Bakı: Elm və təhsil.

Hynes William J. and Doty William G.(1993). Mythical Trickster Figures Contours, Contexts, and Criticisms - Tuscaloosa: University of Alabama press.

Hüseynova Ş. (2018). Türk halk edebiyatında yaşh kar karakterinin taribsel gelisimi - mitlerden masallara, yayınlanmamış bildiri metni. 18.Türk TarihKongresi, 1-5 Ekim. Ankara.

İsmayılov H. (1993). Vatan Qürbatda Qaldı. Bakı. Yazıçı.

Kazımoğlu M. (2005). Gülüs̈̈n arxaik köklari. Bakı. Elm.

Kazımoğlu M. (2006). Xalq gülüşünün poetikası (monoqrafiya). Bakı. Elm.

Türk xalqları folkloru. (2016). IV kitab, Altay dastanlar və afsanalari, Bak1: Elm və təhsil.

Керенъи К. (1999). Трикстер и Аревнегреческая мифология. Пол РаАин. Трикстер. Исследование мифов североамериканских индейцев с комментариями К.Г. Юнга и К.К. Кереньи. Санкт Петербург: Евразия, 288 c., c. 242-264. (Kerenyi Karl.(1999).Trikster v Drevneqreçeskaya mifologiya. Pol Radin. Trkster. İssledovaniye mifov severoamerikanskix indeytsev s kommentariyami K. Q. Yunqa i K.K Kerenyi. Sankt Peterburq: Yevraziya, 288s., c.242-264).

Кинжалов Р. В. (2008). Мифъг народов мира. Электронное Издание, Москва. (Kinjalov Rostislav Vasilyeviç. (2008). Mifi Narodov mira. Elektronnoe İzdanie, Moskva).

Ögel B. (1995). Türk Mitolojisi, 2. Cilt. Ankara. Türk Tarih Kurumu.

Qasımova F. (2012). Türk Mifologiyasinda Madani Qahraman Problemi. Bak1. Elm və təhsil.

Quliyev H. (2016). Müdrik, Qoca arxetipinin semantik strukturu və paradiqmalar. Bakı: Elm və təhsil

Франц Мария-Ауиза фон (2004). Толкование волшебнъцх сказок // Психология сказки. Пер. Р. Березовской и К. Бутырина. - M.: Б.С.К. - 364 с. (Frants Mariya-Luiza fon (2004). Tolkovanie volşebnıx skazok// Psixologiya skazki. Per. R. Berezovskoy i K. Butırina.-M.: B.S.K.- 364 s.).

Гаврилов А.А.(2006). К определенито трикстера и его значимости в сочио-культурной реальности // Первая Всероссийская научная конференция "Философия и социальная динамика XXI века: проблемы и перспективы", 15 мая 2006 г. [материалы]. - Омск: СИБИТ, ИПЭК, СРШБ (колмеАж), -409 с. СС. 359368.(Gavrilov D. A. (2006). K opredeleniyu trikstera i eqo znatsimosti v soçio-kulturnoy realnosti// Pervaya 
Vserossiyskaya nauçnaya konferençiya "Filosofiya i soçialnaya dinamika XXI veka: problemı i perspektivı", 15 maya 2006 q. [materiali]. - Omsk: SİBİT, İPEK, SRŞB (kolledj), - 409 s. SS. 359- 368.

Мелетинский Е.M. (2000). Поэтика мифа. М.: Восточная митература. Meletinskiy E.M (2000). Poetika mifa. M.: Vostoçnaya literatura.

Радин П.(1999). Трикстер. Исследование мифов североамериканских индейцев с комментариями К. Г. Юнга и К. К. Кереньи, СанктПетербург: Евразия, 288 с. (Pol Radin.(1999). Trkster. İssledovaniye mifov severoamerikanskix indeyçev s kommentariyami K. Q. Yunqa i K.K Kerenyi. Sankt Peterburq: Yevraziya, 288 $\mathrm{s})$.

Сказки и предания алтайских тувинщев (1994). Собраны Эрикой Таубе. Авторизованный перевод с немецкого Б.Е. Чистовой. - М.: Издательская фирма «Восточная митература» РАН. «Сказки и мифы народов Востока»). Skazki i predaniya tuvinçev (1994). Sobranı Erikoy Taube. Avtorizovannıy perevod s nemetskoqo B. E. Çistovoy. - M.: İzdatelskaya firma "Vostoçnaya literatura" RAN. ("Skazki i mifı narodov Vostoka")

Юнг К. Г (1999) Психология образа трикстера/ Пол Радин. Трикстер. Исследование мифов североамериканских индейцев с комментариями К.Г. Юнга и К.К. Кереньи. Санкт Петербург: Евразия, 288 с., с.265-286. Jung K. G (1999). Psixologiya obraza trikstera/Pol Radin. Trkster. İssledovaniye mifov severoamerikanskix indeytsev s kommentariyami K. Q. Yunqa i K.K Kerenyi. Sankt Peterburq: Yevraziya, 288s., c.265-286).

\section{Elektronik adres}

Пропп В. Проблемь комизма и смеха (PDF)(Propp Vladimir. Problemi komizma i smexa)(http://royallib.com/book/prop_vladimir/problem_komizma_i_smeha.html)- erişim tarihi: 26.08.20164

FeinbergL. (2004).Mizahın Sırr. Çevirenler: Prof. Dr. Ali Çelik, Dr. F.Gül Özyazıcıoğlu Koçsoy. Milli Folklor, Yıl 16, Say1 62 (http://www.millifolklor.com/PdfViewer.aspx?Sayi=62\&Sayfa=102) -erişim tarihi: 28.07.2018

Stefanova A.Humour Theories and The Archetype of The Trickster In Folklore: An Analytical Psychology Point of View (https://www.folklore.ee/folklore/vol50/stefanova.pdf) - erişim tarihi: 12.08.2018

\section{EXTENDED ABSTRACT}

The character of Trickster has been the research target of folklore researchers for many years. Studies on trickster images have become widespread in world folklore. Foxes, rabbits, shamans, wise men, magicians and other images are included in analytical psychology and folklore as a Trickster. In our article we will talk about the trickster features of the old woman image. Trickster is a liar, cunning, funny, disguised character that causes chaos where it exists and has demonism characteristics. Sometimes the character of Trickster was idolized. But the Trickster is only a deity by nature. The character of the old woman who transformed from mythological texts to folklore texts is Trickster. Starting with myths, usually in myths and epics, the image of the old woman emerging in fairy tales can be considered as a trickster according to some features. Old woman uses these features to achieve her purpose. Mythological characters in a wide range of potentially great significance are transformed from Ulu Ana (Great Mother). Therefore, these characters carry the main symbol of the Ulu Ana. The mythological characters transformed from Ulu Ana have dual aspect. They are neither completely good nor wasteful. Demonic features stem from the mythological origin of the character of the old woman. In the mythological texts, the character of the old woman is Al Karisi, Albast1, Su Ninesi (Water Grandmother) and Umay. In folklore texts, an old woman is a defender of fire, a nanny, a sorcerer, a healer and etc. The old woman sometimes is shaman too. Woman transformed from the Great Mother adopted serious signs. That serious side is dominated in mythological text. But when we look at the epics, fairy tales there appears that funny side have dominated the serious side of old woman. Deceit, craftiness, mendacity are the basic features images of old women.

Shaman is considered trickster too. There are some examples about shaman-trickster old woman in Turkish Mythology. The character of Emegen kari is shaman, even trickster in the Altai's epic, or Jelbege kari from "Begen Saqaan Toolay" fairy tale trickster. The Old woman deceives people makes them believe in herself, sends hero away, or directly helps the hero. The old woman is a deceiver who connects people and gods, the living and the dead.

The feature of trickery is disguise. And old woman is a character who disguise too. There are many examples about disguise of the old woman in Azerbaijan fairy tales: Merchant Gamer, The Snake Boy, The Shirt and etc. There is example of old woman's disguise in the epos of "The Book of DedeKorkut" too. Kysyrdzha Enge and Bohazdzha Fatma are the women who change her appearance. Though they have expressed chaos and cosmos, both of characters are humoruos. Kysyrdzha Enge and Bohazdzha Fatma changing their appearance help Banu Chichek. 
Disguise is an important means for the function of the mythological image. Another feature of the image of the old woman is greedy. In fairy tales and epics, even well-meaning old women are portrayed as greedy. Only negative women are not Trickster. So, women who help heroes can also be Trickster.

When talking about the image of an old woman, it is necessary to emphasize the bald character. Because the image of the bald is often the son or grandson of an old woman in folklore texts. Like the old woman, the image of the bald is demonic creature. In the texts where the bald character is found, there is the character of an old woman too. In folklore texts, an old woman and a bald one is not always a relative. When they are not relatives, there disappear conflict between old woman and bald in fairy tales. In this conflict, the active side is mostly bald. In fairy tales with old woman-bald motifs, the bald is trickery, but the old woman is stupid. As a rule, all these features make the character of an old woman funny. Even in the most serious situation, the old woman creates humor. There is parody of wise, stupid, and trickster in these motives. The image of old woman is mythological and demonological in folk literature. At the same time, old woman is the character that creates humor in the folklore. This humor is based on the proximity of the mythological character trickster with the character of a woman. The old woman sometimes is good, sometimes bad, sometimes funny, sometimes dramatic situations, sometimes wise, sometimes sly. There are many reasons to think old woman is a trickster. And the aim is to define the place of the old woman among the other trickster characters. 